Portland State University

PDXScholar

1983

\title{
Sex differences in the language development rates of two-year olds
}

Laurel A. Hickman

Portland State University

Follow this and additional works at: https://pdxscholar.library.pdx.edu/open_access_etds

Part of the Child Psychology Commons, and the Speech and Rhetorical Studies Commons Let us know how access to this document benefits you.

Recommended Citation

Hickman, Laurel A., "Sex differences in the language development rates of two-year olds" (1983). Dissertations and Theses. Paper 3273.

https://doi.org/10.15760/etd.3263

This Thesis is brought to you for free and open access. It has been accepted for inclusion in Dissertations and Theses by an authorized administrator of PDXScholar. Please contact us if we can make this document more accessible: pdxscholar@pdx.edu. 
AN ABSTRACT OF THE THESIS OF Laurel A. Hickman for the Master of Science in Speech Communication, with an emphasis in Speech-Language Pathology, presented April 26, 1983.

Title: Sex Differences in the Language Development Rates of Two-Year Olds.

APPROVED BY MEMBERS OF THE THESIS COMMITTEE:

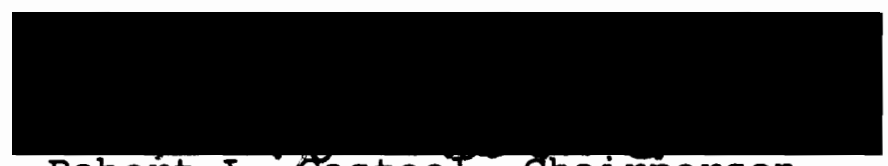

Robert L.-casteel, Chairperson
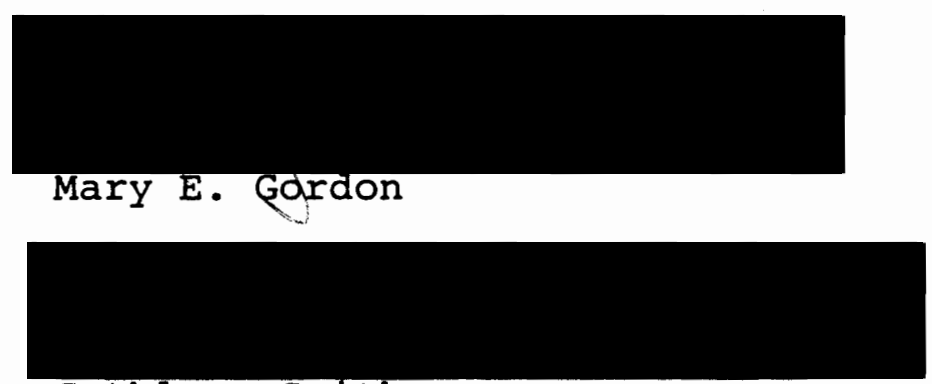

Cathleen Smith

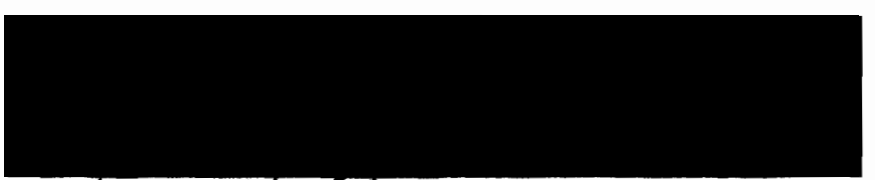

Eric A. Kimmel

The purpose of this study was to examine and compare the language development rate of male and female children, 24 to 30 months of age, during a three month time period. The research question was: in two year olds, is there a significant difference between males and females over a 
time period of three months in rate of language growth as measured by mean length of utterance (MLU)?

Early studies conducted in the 1930's and 1940's support sex differences in language development. McCarthy (1954) reported sex differences in fourteen of these studies involving mean length of response (MLR). The differences in children under the age of three years always favored girls. McCarthy postulated that the consistency of the direction of the differences constituted a "significant trend." The studies presented in the Review of the Literature section are consistent with this "significant trend" hypothesis; the overwhelming majority show differences which favor girls.

Sixteen subjects, aged 24 to 29 months, were chosen for this study from private homes in the Greater Portland area. Each subject was sampled in the home while interacting with the mother. Three months after the initial sample was taken, each child was again sampled during interaction with the mother.

Screening Mean Length of Utterance analysis was performed from the transcripts produced from the thirty-two examinations conducted by the investigator. Statistical analysis was by a Wilcoxon Rank Sum Test for independent measures. Nonsignificant differences were found which favored girls. This is consistent with earlier studies concerning sex differences (McCartiny, 1954). 
SEX DIFFERENCES IN THE LANGUAGE

DEVELOPMENT RATES OF TWO-YEAR OLDS

by

LAUREL A. HICKMAN

A thesis submitted in partial fulfillment of the requirements for the degree of MASTER OF SCIENCE IN SPEECH COMMUNICATION:

with an emphasis in SPEECH-LANGUAGE PATHOLOGY

Portland State Unviersity

1983 
TO THE OFFICE OF GRADUATE STUDIES AND RESEARCH:

The members of the Committee approve the thesis of Laurel A. Hickman presented April 26, 1983.

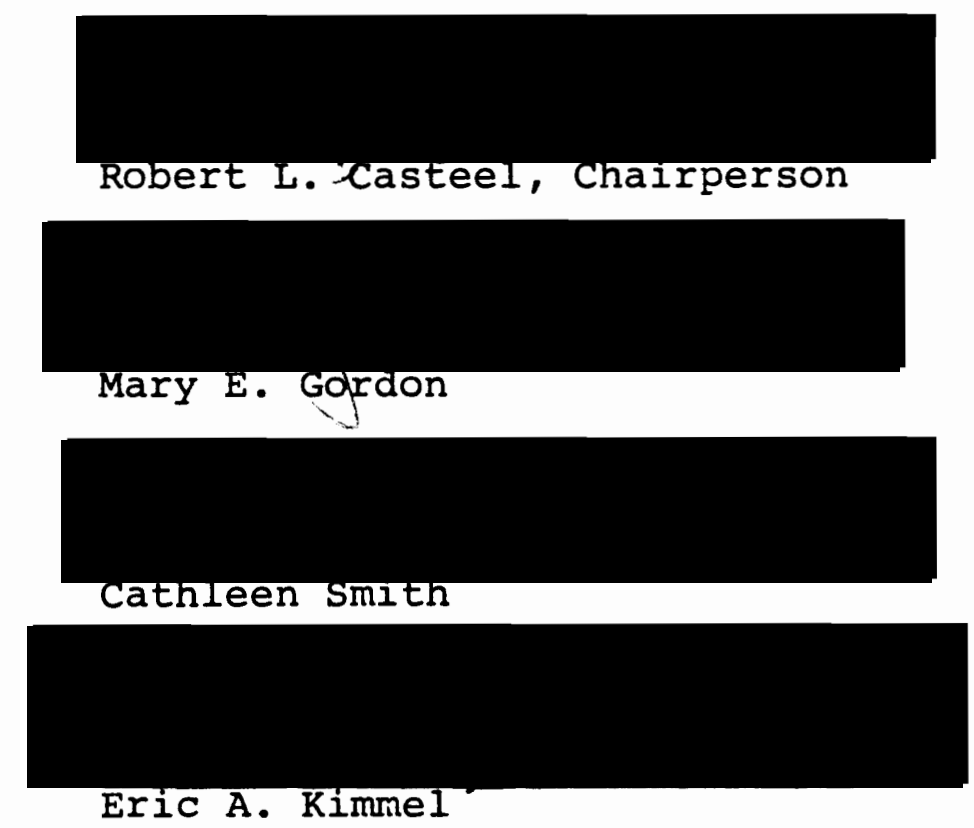

APPROVED :

Wheodore G. Grove, chalr, Department of Speech Communication

Stanley E. Rauch, Dean, Graduate

Studies and Research 


\section{ACKNOIVLEDGEMENTS}

sincere thanks to

Robert Casteel

Mary Gordon

Cathleen Smith

Eric Kimmel

Karen Lucas

Cathy Thompson

Carol Kafton-Minkel

Subjects and Their Mothers

I dedicate this thesis to Roger Hickman, my physical, mental, emotional, and spiritual support throughout. Thank you, Musser. 
TABLE OF CONTENTS

Page

ACKNOWLEDGEMENTS

iii

LIST OF TABLES

CHAPTER

I INTRODUCTION . . . . . . . . . . . 1

Statement of Purpose . . . . . . . . . 3

Definitions .............. . 4

II REVIEW OF THE LITERATURE . . . . . . . . 5

Mean Length of Utterance . . . . . . 5

Studies Supporting Sex Differences
in Language Development . . . . . . 7

Studies Which Do Not Support Sex
Differences in Language Development . 14

Summary ............... . 17

III METHODS ............... 20

Subjects ... . . . . . . . . 20

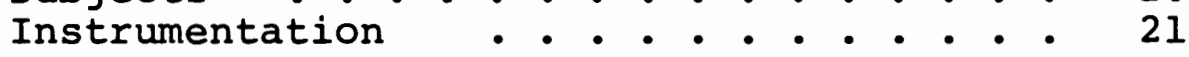

Procedures . . . . . . . . . . . 23

Reliability .............. 24

Analysis of the Data . . . . . . . . 25

IV RESULTS AND DISCUSSION . . . . . . . . . 26

Results ............... 26

Discussion .............. 27

V SUMMARY AND IMPLICATIONS ........ . 30

Summary ............. . 30

Implications for Future Research ... . 31

SELECTED BIBLIOGRAPHY . . . . . . . . . . . . . 33

APPENCICES . . . . . . . . . . . . . . . 35 


\section{LIST OF TABLES}

TABIE

Page

I Female and Male Data . . . . . . . . . . 22 
CHAPTER I

INTRODUCTION

Sex differences in language acquisition have been the topic of discussion and research by educators, linguists, speech-language pathologists, and lay people for many years (McCarthy, 1954; Templin, 1957; Maccoby and Jacklin, 1974; Ramer, 1976; Eakins and Eakins, 1978). Older studies generally have shown small and sometimes significant differences in favor of females; more recent research, however, has not found female superiority in language development.

In 1978, Shachter, Shore, Hodapp, Chalfin, and Bundy conducted a study measuring the mean length of utterance (MLU), mean length of response ( $M L R$ ), and the mean of the five longest utterances in words and in morphemes. One hundred and thirty children between the ages of 23.80 and 28.57 months were assessed. Male and female subjects were matched for age, socioeconomic status (SES), and race. These authors questioned the reported discrepancy between the earlier research on language development which had consistently indicated that girls were more advanced verbally than boys, and the more recent research which tended to show little or no difference in language development. The authors theorized that the discrepancy could be due to a change in methodological approach. The earlier studies provided data on sizable 
samples of toddlers (McCarthy, 1954), while later studies failed to use samples of adequate size (Bloom, 1970; Brown, 1973). Additionally, earlier studies included data on sentence length, while the newer studies were concentrating on sentence complexity (Lee, 1974), age of appearance of first word (Darley and Winitz, 1961), comprehension of language (Moore, 1967), and vocabulary (Maccoby and Jacklin, 1974). The results of the Schachter et al. (1978) study showed that girls were significantly advanced in MLR, MLU, and mean of five longest utterances in words (beyond the .05 significance level), and mean of five longest utterances in morphemes (beyond the .01 significance level) during the first (Fall) semester. During the second (Spring) semester, girls, who were five months older than the Fall semester girls, were advanced in MLU and MLR but not significantly ( $p$ values ranging from .07 to .15). However, the mean of the five longest utterances in words and morphemes revealed the girls to be significantly advanced over boys (beyond the .01 level). The authors stated that their results were better than the more recent research for comparison purposes with the early sex differences studies because they had replicated the older studies by utilizing MLR as a measure and obtained similar results to those obtained in the earlier research. More importantly, they utilized MLU as a measure and obtained significant differences between the younger toddler girls and boys beyond the .01 level of significance. The authors stated that a measure of $\mathrm{MLU}$ was the soundest approach to the problem 
of sex differences in view of the "recent advances" in psycholinguistics which identify the toddler period (approximately 18-36 months) as the most rapid phase of language development and the MLU as the index that best reflects progress during this phase.

In 1974, Maccoby and Jacklin reviewed the literature concerning sex differences in several areas of development. In the areas of spontaneous vocal and verbal abilities, they reviewed over sixty studies. Their summary of the results led them to hypothesize two distinct phases in the development of verbal abilities in which there are sex differences. The first occurs before the age of three years. They stated that by the age of three the boys achieved parity. This hypothesis is consistent with the findings of schachter et al. (1978) in which the younger toddler girls were significantly advanced in MLU and MLR, but the older toddler girls were not.

The literature at this time is unclear concerning the developmental differences between the sexes; that is, how the development of boys and girls can evidence differences at eighteen months and little difference after three years.

\section{Purpose}

The purpose of this study was to examine and compare the language developmental rate of male and female children, 24 to 30 months of age, during a three month time period. The research question was: in two year olds, is there 
a significant difference between males and females over a time period of three months in rate of language growth as measured by mean length of utterance (MLU)?

The followng operational definitions should aid in understanding the language in the review of the literature.

\section{Definitions}

DEVELOPMENTAL SENTENCE ANALYSIS (DSA): a measure which assesses a child's incorporation of adult grammatical rules into his or her spontaneous speech from a recorded language sample (Lee, 1974).

DEVELOPMENTAL SENTENCE SCORING (DSS): the method by which a child's syntax development is specified by weighted scoring of specific grammatical structures in complete sentences (Lee, 1974).

DEVELOPMENTAL SENTENCE TYPES (DST): a measure of sentence complexity utilized with children who do not exhibit at least 50 percent complete sentences in their speech; in this measure, four levels of word combinations which range developmentally from two-word combinations, to noun phrases, to constructions, to sentences are used to specify the childs' developmental level (Lee, 1974).

MEAN LENGTH OF RESPONSE ( MLR): this term characterizes verbal output in terms of average sentence length measured in words (McCarthy, 1930).

MEAN LENGTH OF UTTERANCE (MLU): an index used to measure grammatical development. In the early stages of language acquisition it is sensitive to the increase in linguistic knowledge. MLU is calculated by using 100 different consecutive utterances of a language sample, and dividing the number of morphemes by 100 (Brown, 1973).

PSYCHOLINGUISTICS: the joint study of psychology and linguistics which attempts to interrelate human behavior and culture with language ( Perkins, 1977).

SCREENING MLU: calculated by using 50 different consecutive utterances of a language sample, and dividing the number of morphemes by 50 .

SENTENCE COMPLEXITY: grammatical complexity and completeness of utterances in a sentence. 
CHAPTER II

REVIEW OF THE LITERATURE

Children's language acquisition has been determined by means of language sampling in a naturalistic environment for over fifty years (McCarthy, 1930; Barrie-Blakeley, Musselwhite, and Rogister, 1978). The types of analysis have varied. Mean length of response (MLR), the average number of words per sentence, was an early measure developed to characterize verbal output (Nice, 1925; McCarthy, 1930). Nice (1925) suggested that

- . this average sentence length may well prove to be the most important single criterion for judging a child's progress in the attainment of adult language.

More recently, investigators have used mean length of utterance (MLU), the average number of morphemes per sentence, as a measure of utterance length. The MLU emphasizes linguistic complexity more than does MLR, and is presumed to be more sensitive as a measure for language analysis (Brown, 1973; Barrie-Blakeley et al., 1978). In effect, one is a quality assessment and the other is a quantity assessment.

\section{Mean Length of Utterance}

MLU is an independent measure not related to chronological age. It is, instead, related to language age. Dale (1976) reports that although MLU is a crude measure, it may 
be the "best single indicator of language development, at least for children of age five and under." Despite Nice's (1925) prediction that MLR "may well prove to be the most important single criterion" in assessing the language development of children, and although MLR is still utilized as an assessment tool by clinicians, later researchers discovered that MLU was far more sensitive to developmental changes in preschool children (Brown, 1973; Miller and Chapman, 1981). Brown (1973) studied the emergence of what he called the fourteen "grammatical morphemes." He used this term to refer to morphemes whose primary purpose is to modify the meaning of content words or indicate the relations of content words more precisely (see Appendix A). Brown found the order of these morphemes in childrens' language to be very similar; if two children are chosen at random, the rank order correlation between the two children's order of acquisition will be between .80 and .90 . Furthermore, Brown found that the child's MLU could predict the presence or absence of an individual morpheme in the child's verbalizations. Similarly, Dale, (1976) reports that the correlation between the child's age and the order of acquisition is .68; the correlation between MLU and order is .92.

Brown (1973) presented five stages through which the child goes through in his development of language. Stage I is described by Brown as the period beginning with the emergence of the first multiword utterances and continuing until MLU reaches 2.0. Dale (1976) has stated the absence of 
inflections "virtually defines" Stage I speech.

In Stage II, children have acquired the basic relations and are combining morphemes into more complex and longer strings of words (Brown, 1973). Utterances are altered to include the nuances of meaning which Brown calls 'modulation'; the inflections begin to be mastered in this stage. MLU is between 2.0 and 2.5 (Dale, 1976).

Brown (1973) refers to stage III as "modalities of the simple sentence" and specifies that this stage begins with an MLU of 2.5 and ends with an MLU of 3.0. The modalities Brown refers to here are the development of interrogation, negation, and the imperative. In Stage IV, which begins with an MLU of 3.0, children utilize transitive verbs (e.g., think, know, guess, tell) to embed one sentence within another. Finally, Stage $\mathrm{V}$ is called "Coordination of Simple Sentences and Propositional Relations" and begins with an MLU of 4.0. Children in this stage use the conjunctions (e.g., and, but, if, and then, etc.) to combine two complete sentences. As was discussed previously, the MLU of an individual child correlated .92 with that child's order of morpheme acquisition; these stages not only represent increments of .5 through Stage III and 1.0 thereafter, but progressive stages in the development of language (Brown, 1973; Dale, 1976).

Studies Supporting Sex Differences in Language Development

McCarthy (1954) presented a comprehensive summarization 
of cross-sectional investigations into sex differences in the development of language skills. She summarized these investigations by stating:

- . the present findings with regard to sex differences in verbosity and vocabulary indicate that girls tend quite consistently to surpass boys, but not to a degree that is statistically significant. . . the vast accumulation of evidence in the same direction from a variety of investigators working in different parts of the country, employing different analyses and linguistic indices, certainly is convincing proof that a real difference in language development exists in favor of the girls. . . in the data cited above, there is presented experimental, rather than statistical, evidence of the reality of the differences, small though they may be; and when experimental trends check in study after study there appears to be little need for the reassurances of statistical significance.

McCarthy indicated that the differences in all the studies she reviewed on MLR, vocabulary, and verbosity either favored girls, or were explainable in terms of choice of language elicitation materials, or choice of lower socioeconomic status (SES) girls as subjects compared to higher SES boys. The data in some but not all of these studies, reached the level of significance, however, the author does not provide information about which studies reached the level of significance.

A longitudinal study of the first eight years of language and intellectual development in boys and girls was conducted by Moore (1967). Seventy-six subjects (thirty-eight males and thirty-eight females) were tested at six months, one and one-half, three, five, and eight years. The measures used were the Griffiths Scale of Infant Development: GQ Speech Quotient, and the Stanford Binet: IQ, Vocabulary. 
While tested on these measures, the subjects were rated for comprehension of language (at three, five, and eight years), amount of vocalization (at six months), and verbal communicativeness or MLR (at eighteen months and three years). Results showed that the girls surpassed the boys by ten points in the speech quotient (based on the hearing and speech section of the Griffiths Scale). This difference was significant beyond the .05 level of significance.

In 1974, Maccoby and Jacklin reviewed the literature concerning sex differences in several areas of development. In the areas of spontaneous vocal and verbal abilities they presented the results of over sixty studies. They stated that the conclusions concerning sex differences in language development in the first few years of life were based on studies from the 1930's to 1940's. Since that time, the authors claim, there have been almost no normative studies with children under the age of three years. The work in the field of language development rather has focused on

- . small and rather highly selected groups of children. It does not reveal whether there has been a relative change in the standing of the two sexes at these early ages. .

The small scale studies were presented by the authors to "indicate that the presumed advantage of girls in the first two years of life is tenuous." These studies further indicate no apparent "trends" in the amount of spontaneous talking that the two sexes do "in the course of their daily activities." The authors concluded that "whether a sex difference would 
still be found with large samples. - on mean length of utterance we do not know." In addition, they concurred with McCarthy's 1954 conclusions: "However, when there was a difference it almost always favored girls, and the many studies taken together added up to a significant trend."

Ramer (1976) conducted a longitudinal investigation of the emerging grammar of seven children aged one year, three months to two years, three months. Four girls and three boys were seen in their homes by the investigator for two hours once every three weeks from the time prior to the onset of syntax (production of two or more words, within one intonation framebounded initially and finally by a pause) for all the subjects until the time when 20 percent of the child's utterances utilized a combination of subject verb complement (SVC) structure. Data were analyzed and interpreted utilizing a modified form of Bloom's (1973) technique for determining grammatical relations based on semantic intent. The semantic intent for each utterance was determined on the basis of three types of situational information: 1) the non-linguistic content; 2) the preceeding adult utterance; and 3 ) the child's own utterance immediately following the utterance under analysis.

Results showed a variance among the children from the time of the first syntactic utterance to the 20 percent cutoff SVC structure of two and one-half to nine months. All the boys in the study were revealed to be "slow syntactic developers," while the girls' syntactic development was reported 
to be "rapid."

The author concluded that not only was the girls' acquisition more rapid, but they also employed a syntactic style which differed from the boys'. Girls were reported to; employ few syntactic forms, move toward syntactic complexity more smoothly, stray from adult English word order, and specify SV, SC, and VC grammatical relations from the onset of syntax. Boys on the other hand were found to; depend heavily on presyntactic forms, appear to have difficulty acquiring higher levels of complexity, observe adult English word order constraints, and tend to specify VC relation as their first approach to syntax.

Klein and Durfee (1978) assessed the social behavior of forty infants (twenty males and twenty females) by means of time-sampled observations, ratings, and interviews. The subjects were each seen four times. The average chronological age at the first session was 11.8 months; at the fourth session the average age was 12.9 months. The first two sessions involved seeing the child at home. Mothers were instructed to "go about your daily routine and ignore the observer as much as possible." In the third and fourth sessions, the child was observed during a free play situation in the laboratory while the mother was being interviewed. Results were assessed on a scale of one-to-five on the following variables :

MUTUAL PLAY: Mother and infant interact with same object, or mother and infant are involved in an 
exchange in which social components predominate. POSITIVE COMMUNICATION: Infant smiles to, vocalizes to, or shares an object with the mother. PROXIMITY CONTACT: Infant approaches, follows, reaches toward, or touches the mother. POSITIVE TO OBSERVER: Infant approaches, touches, smiles, or vocalizes to the observer. MATERNAL INTERACTION: Mother vocalizes to, touches, holds, moves, gives objects to or takes objects from infant.

Results revealed Positive Communication to be the only variable which yielded significant differences. These differences were in favor of the girls. Mothers of girls, however, were found to interact more with their infants than mothers of boys. Because of these relationships, the data were re-analyzed using amount of maternal interaction as a covariate. Then this was done, Positive Communication still showed a significant difference in favor of girls. In addition, Positive to Observers, which had not previously produced significant results, now revealed a difference in favor of girls. Positive Communication was further analyzed by each of its components. In the home, girls scored higher on Positive Vocalization and social sharing. After controlling for amount of maternal interaction, the difference in favor of girls for Positive Vocalization and for social sharing remained significant. In the laboratory only Positive Vocalization showed a sex difference, with girls again scoring significantly higher than boys (mean of 17.15 to 10.35 mean).

In 1978, Schachter, Shore, Hodapp, Chalfin, and Bundy conducted a study which replicated the methodology of the older studies which found sex differences in language 
development. Schachter et al. measured the MLR of one-hundred and thirty children between the ages of 23.80 and 28.57 months (sexes were matched for age, SES, and race). These authors theorized that the discrepancy between the earlier research on sex differences in language development in children and the more recent research could be due to a change in methodological approach. According to the authors, the older studies provided data on MLR in sizable samples of toddlers, while the newer studies failed to present data on toddler samples of adequate size. The authors stated that a measure of sentence length was the soundest approach to the problem of sex differences in view of what they called "recent advances" in psycholinguistics which identifies the toddler period (approximately 18-36 months) as the most rapid phase of language acquisition and the MLU as the index that best reflects progress during this phase. They cited support for their criticism in the form of a list of recent studies, the majority of which concentrated on vocabulary, verbal fluency, and language comprehension. Additionally, they presented the recent studies on MLU and stated that the samples were, in all cases, too young, too old, or too small.

Data were collected over a four year period on subjects attending the Barnard College Toddler Center, a universitybased play group. The toddlers attended five hours a week for two twelve week semesters in the Fall and spring. The investigators identified as subjects those children who had reached the stage of two word utterances. Fifty utterances 
were collected from each subject; to ensure a representative sample of each subjects' speech, toddlers were observed in random order for intervals of three minutes each for as many of such intervals as were needed to collect fifty utterances. The data were analyzed utilizing four indices: 1) MLU:

2) MLR: 3) upper bound or longest utterance in words; and 4) upper bound in morphemes.

Results of the Schachter et al. (1978) study showed that girls were significantly advanced in MLU, MLR, and upper bound in words (beyond the .05 level of significance), and upper bound in morphemes (beyond the .01 level of significance) during the first (Fall) semester. During the second (Spring) semester, girls who were five months older were advanced in MLU and MLR, but not significantly ( $p$ values ranging from .07 to .15$)$. Upper bound in words and morphemes however, revealed girls to be advanced significantly over boys.

Studies Which Do Not Support Sex Differences in Language Development

In 1957 Templin reported that in the studies she reviewed involving MLR in preschoolers, girls tended to receive higher scores than boys. The differences were not, however, consistent, and were only significant at the age of five years (beyond the .05 level of significance).

An investigation by Winitz (1959) was conducted to discover if the "previously reported and tentatively small differences favoring female children are chance differences or 
real differences which would be significant with large samples." The subjects were one hundred and fifty randomly selected, normal five year old children. The groups were matched for chronological age, intelligence quotient (IQ), socioeconomic status, and family constellation. A language sample was taken and the sexes were compared on the following measures: MLR, mean number of words in the five longest responses, mean standard deviation, the number of different words, and structural complexity. Results of these measures revealed that the direction of differences for all six verbalizations favored the girls. The differences were significant, however, in the case of only two measures: The mean of the five longest responses and the mean standard deviation. Winitz concluded that the differences exhibited in the results of his study were not of "sufficient magnitude to justify regarding the groups as essentially different in verbalization skills." For this reason, he stated that investigations to explain sex differences and the practice of considering male and female verbal skills different clinically were contraindicated. The author further stated that even though the $\underline{t}$ values in all instances approached significance in this study (possibly indicating that significant results would be obtained with larger samples)

Both the cost of conducting such an expanded investigation and the possible limited usefulness of the results make the practicability of such an investegation questionable (Winitz, 1959).

He further stated that the effect of examiner sex (male) on 
the females was probably not significant

- . since children in the present culture typically interact with members of both sexes, it would seem that the sex of the examiner is not an important source of error (Winitz, 1959).

Darley and Winitz (1961) reviewed the literature concerning age of appearance of first word. Results reported in twenty-six studies lead these authors to conclude there was little evidence to indicate that girls begin to speak significantly earlier than boys as measured by age of appearance of first word. Of the twenty-six studies presented, however, only six included data on the breakdown between boys and girls with the remaining twenty studies combining the data. The six studies presenting differences in the data by sex indicated the following: in five studies girls spoke their first word between one and five months earlier than boys; in one study, involving children with delayed articulation and/or language, the girls spoke their first word an average of three weeks later than the boys.

Middle class females from two years to six years, eleven months of age were reported by Lee (1974) to produce language samples that received higher developmental sentence scoring (DSS) scores. Lee noted, however, that significant differences between the sexes were not found at the two and three year level which according to the author was the language age level at which the DSS was most often used clinically. For this reason, "normative chartings of the DSS for clinical comparisons - . are based upon the combined male and female 
subject data."

\section{Summary}

Early studies conducted in the 1930's and 1940's support sex differences in language development. McCarthy (1954) reported sex differences in fourteen of these studies involving MLR; of these fourteen studies, ten included data on children age three years and under. The differences in this age group, while not always significant, always favored girls. Additionally, sample sizes in these studies were large in comparison to later studies; sample sizes ranged from twentythree to one thousand subjects with all but two of the fourteen studies involving samples of over one-hundred subjects. In her conclusion, McCarthy postulated that the consistancy of the direction of the differences constituted a "significant trend." The studies presented in this chapter are consistent with this "significant trend" hypothesis; the overwhelming majority show differences which favor girls.

A few studies not supporting sex differences in the language development of children under the age of three years have been reported. Templin (1957) found no significant differences between boys and girls under the age of three years, but her studies represented sample sizes of between eighteen and forty-two subjects. Darley and Winitz (1961) reviewed the literature concerning age of appearance of first word and concluded there was little evidence to indicate that girls begin to speak significantly earlier than boys as measured 
by age of first word, even though the majority of the studies they reviewed did not include data which was separated for the sexes; of the six studies which provided data, only one presented data which showed differences favoring boys, with the remaining five studies revealing differences in favor of girls. Finally, Lee (1974) did not find significant differences between girls and boys under the age of three in DSS scores.

Mention must be made of the ambiguity of many of the investigators' conclusions regarding sex difference studies. What two investigators have called "little evidence" (Darley and Winitz, 1961), would be support for another investigator's hypothesis of a "significant trend" (McCarthy, 1954). In spite of the lack of statistical support for differences between the sexes, the studies reviewed here favored girls. Thus, some investigators chose to interpret the results as support for the hypothesis of the precocity of girls in language development, even when the differences did not reach the level of significance (McCarthy, 1954; Maccoby and Jack1in, 1974). Other investigators interpreted similar results as evidence that there were not sex differences in the language development of young children, which is a conclusion drawn from a few studies involving small samples of children (Templin, 1957; Darley and Winitz, 1961) or measures other than MLU (Lee, 1974). In 1974, Maccoby and Jacklin stated the controversy accurately when they concluded "Whether a sex difference would still be found with large samples on 
mean length of utterance, we do not know . . ." Schachter et al. (1978) concluded that the older studies involving sentence length were valid in their indication of earlier language development on the part of females.

Up to this time, there has been a lack of Iongitudinal research in the area of sex differences in childrens' language development. A longitudinal study would be the only means of determining whether or not the sex differences in rate of language growth are detectable. The present study was conducted to determine whether the rates of language development as measured by screening MLU over a time period of three months were different for two year old males and females. 
CHAPTER III

METHODS

\section{$\underline{\text { Subjects }}$}

Sixteen subjects (seven male, nine female) were chosen for this study from private homes in the Greater Portland area. Subjects' names were obtained through an infant swimming class roster and from asking mothers of the subjects for the names of other two year olds. For the first language sample, the children ranged in age from twenty-four to twentynine months. For the second language sample, the age range was twenty-seven to thirty-two months. Children with hearing losses, physical or mental handicaps, obvious expressive language delay, or who were the product of multiple birth were excluded. It was assumed, for the purposes of this study, that by passing the Boyd Developmental Progress Scale (Boyd, 1974), the child exhibited normal hearing acuity, physical and mental ability, and expressive language development. The subjects came from two parent families, and the language spoken in the home was Standard American English.

Socioeconomic computation for the subjects' families was determined by the first two questions from Working Paper No. 15 from the U.S. Bureau of Census (1960). The SES scores of subjects' families ranged from fifty-one to ninety-eight, 
representing middle to upper SES families. Females mean SES score was 78.05, males was 69.29. The standard deviation for the group's SES scores was 11.50 , and the difference between males and females was not significant (see Table I).

All the subjects were screened by the investigator with the age level items from the Boyd Developmental progress Scale (see Appendix B). All subjects passed the two-year criterion, and none passed the three-year criterion.

\section{Instrumentation}

A Sony TCM-280 tape recorder with a Sony F-V3T attachable microphone was used to record the sessions.

Screening Mean Length of Utterance rules were used to calculate the subjects' length of utterance in the transcribed language samples (Brown, 1973). The rules for calculating MLU in this project were:

1. Only fully transcribed utterances were used; however, portions of utterances entered in parentheses to indicate doubtful transcription, were used.

2. Included were all exact utterance repetitions. "Stuttering" was marked as repeated efforts at a single work; and the word was counted once in the most complete form produced. If a word was repeated for emphasis (e.g., no, no, no), each occurrence was counted.

3. Fillers such as "mmm" or "oh" were not counted, but "no, yeah, and hi" were counted.

4. All compound words (two or more morphemes), proper names, and ritualized reduplications counted as single words. Examples are: birthday, night-night.

5. Counted as one morpheme were all irregular pasts 
TABLE I

FEMALE AND MALE DATA

\begin{tabular}{|c|c|c|c|c|c|c|}
\hline \multicolumn{7}{|c|}{ FEMALES } \\
\hline CHILD & AGE & SES & SESSION & $\# 1$ & SESSION $\# 2$ & CHANGE \\
\hline $\begin{array}{l}A \\
B \\
C \\
D \\
E \\
F \\
G \\
H \\
I\end{array}$ & $\begin{array}{l}24 \mathrm{mos} \\
24 \mathrm{mos} \\
24 \mathrm{mos} \\
26 \mathrm{mos} \\
26 \mathrm{mos} \\
27 \mathrm{mos} \\
28 \mathrm{mos} \\
28 \mathrm{mos} \\
28 \mathrm{mos}\end{array}$ & $\begin{array}{l}78.5 \\
69.0 \\
76.0 \\
86.0 \\
57.5 \\
98.5 \\
77.0 \\
84.0 \\
76.0\end{array}$ & $\begin{array}{l}1.66 \\
1.62 \\
1.90 \\
2.10 \\
2.00 \\
2.08 \\
1.54 \\
1.94 \\
3.62\end{array}$ & & $\begin{array}{l}1.60 \\
1.96 \\
2.24 \\
2.74 \\
2.28 \\
2.12 \\
2.28 \\
2.06 \\
3.10\end{array}$ & $\begin{array}{r}-.06 \\
.34 \\
.34 \\
.64 \\
.28 \\
.04 \\
.74 \\
.12 \\
-.52\end{array}$ \\
\hline $\begin{array}{l}\text { MEAN } \\
\text { S.D. }\end{array}$ & 26.11 & 78.05 & $\begin{array}{r}2.05 \\
.62\end{array}$ & & $\begin{array}{r}2.26 \\
.44\end{array}$ & $\begin{array}{l}.21 \\
.38\end{array}$ \\
\hline \multicolumn{7}{|c|}{ w/o "I" } \\
\hline $\begin{array}{l}\text { MEAN } \\
\text { S.D. }\end{array}$ & 25.88 & 78.31 & $\begin{array}{r}1.86 \\
.22\end{array}$ & & $\begin{array}{r}2.16 \\
.32\end{array}$ & $\begin{array}{l}.31 \\
.28\end{array}$ \\
\hline \multicolumn{7}{|c|}{ MALES } \\
\hline $\begin{array}{l}A \\
B \\
C \\
D \\
E \\
F \\
G\end{array}$ & $\begin{array}{l}24 \text { mos } \\
24 \text { mos } \\
25 \text { mos } \\
25 \text { mos } \\
26 \text { mos } \\
28 \text { mos } \\
29 \text { mos }\end{array}$ & $\begin{array}{l}74.0 \\
66.0 \\
68.0 \\
86.0 \\
71.0 \\
51.0 \\
69.0\end{array}$ & $\begin{array}{l}1.94 \\
1.30 \\
1.40 \\
1.28 \\
2.86 \\
1.82 \\
2.96\end{array}$ & & $\begin{array}{l}1.64 \\
1.76 \\
1.74 \\
1.58 \\
2.74 \\
2.12 \\
2.74\end{array}$ & $\begin{array}{r}-.30 \\
.46 \\
.34 \\
.30 \\
-.12 \\
.30 \\
-.22\end{array}$ \\
\hline $\begin{array}{l}\text { MEAN } \\
\text { S.D. }\end{array}$ & 25.86 & 69.29 & $\begin{array}{r}1.94 \\
.71\end{array}$ & & $\begin{array}{r}2.05 \\
.50\end{array}$ & .11 \\
\hline \multicolumn{7}{|c|}{ GROUP } \\
\hline $\begin{array}{l}\text { MEAN } \\
\text { S.D. }\end{array}$ & $\begin{array}{r}26 \\
1.79\end{array}$ & $\begin{array}{l}74.21 \\
11.50\end{array}$ & $\begin{array}{r}2.00 \\
.64\end{array}$ & & $\begin{array}{r}2.17 \\
.46\end{array}$ & $\begin{array}{l}.17 \\
.34\end{array}$ \\
\hline
\end{tabular}


of the verb (e.g., got, did, went, saw).

6. Counted as one morpheme were all diminutives (doggie, mommie).

7. Counted as separate morphemes were all auxiliaries (e.g. is, have, will, can, must, would); also catenatives: gonna, wanna, hafta. Counted as separate morphemes were all inflections (e.g., possessive (s), plural (s), third person singular (s), regular past (d), progressive (i) ).

\section{Procedures}

In gathering the language sample from which to compute the screening Mean Length of Utterance, the following procedures were utilized: subjects were given the Boyd Developmental Progress Scale prior to the sampling. Those subjects passing this scale were sampled in the home while interacting with the mother.

Three months after the initial sample was taken, each subject was again sampled during interaction with the mother. A parent consent form was signed by the mother at the time of the first sample (see Appendix $C$ ).

Each mother was given written instructions about her part in the language sample (see Appendix D). The subjects and their mothers were given toys to play with (see Appendix E). The investigator was present throughout the taping to operate the recorder. At no time did the investigator interact with the child verbally during the taping session. Three months after the initial sample was taken each child was again sampled during interaction with the mother in the home. At 
each sampling session the mothers were given typed instructions regarding their role in gathering the language sample and were given the opportunity to ask questions regarding their role, the situation and materials used for language stimulation. The taped language session was transcribed to a typed manuscript by the investigator (see Appendix F).

\section{$\underline{\text { Reliability }}$}

Two judges and the investigator were used in the MLU interjudge reliability examination. The judges were graduate students in speech-language pathology with past experience in transcribing language samples.

Typed instructions (see Appendix F) were prepared and taped training samples of speech episodes were provided on tape for the judges during a training session. The three taped episodes demonstrated types of judgements which must be made in MLU analysis.

Following the training session, thirty-two speech samples were chosen at random from the thirty-two available tapes (one sample per taped session) and presented independently to the judges for MLU analysis. From each of these samples, five utterances were scored by each of the judges. Eight samples were later chosen from the thirty-two and presented for a measure of intra-judge reliability. All judges demonstrated a mean of 94 percent agreement on the test-retest samples. Inter-judge reliability was a mean of 92 percent for all judges and from these data the investigators' ability 
to accurately perform MLU analysis was deemed adequate.

\section{Analysis of the Data}

Two screening-MLU language samples were transcribed for each of the subjects. Analysis of the data was by a wilcoxon Rank Sum Test for independent samples (McClane and Dietrich, 1982) to determine the amount of change between males and females for the change score. In addition, the Wilcoxon signed Rank Test for a paired experiment (McClane and Dietrich, 1982) was performed to determine if there was a significant rise in MLU from session number 1 to session number 2 for the females as a group, and then for the males as a group. 
CHAPTER IV

RESULTS AND DISCUSSION

Results

A Screening Mean Length of Utterance analysis was performed upon the transcripts produced from the thirty-two examinations conducted by the investigator. Statistical analysis was by the Wilcoxon Signed Rank Test for a paired experiment (McClane and Dietrich, 1982) to determine intra-group significance for the change score, and by a wilcoxon Rank sum Test for independent measures (McClane and Dietrich, 1982).

Preliminary to comparison of male and female change scores, the Wilcoxon Signed Rank Test for a paired experiment was performed to determine if there was a significant rise in MLU from session number 1 to session number 2 for the females as a group, and then performed separately for the males as a group. Results of this test indicated that the amount of change for both the males and the females was not significant between session number 1 and session number 2 (see Appendix G) .

A Wilcoxon Rank Sum Test for independent measures comparing the differences between males and females in change score revealed no differences in the change scores for males and females (see Appendix $\mathrm{H}$ ). 
As indicated in Table $I$, the girls' MLU scores in the samples taken by the investigator ranged from 1.54 to 3.62 (mean $=2.05)$ on the first sample, and from 1.60 to 3.10 (mean $=2.26)$ on the second sample. Males' scores ranged from 1.28 to 2.96 (mean $=1.94$ ) on the first sample, and from 1.58 to 2.74 (mean $=2.05$ ) on the second sample. As already indicated, these differences were not significant.

For the change score, females ranged from -.52 to .74 $($ mean $=.21) ;$ males ranged from -.30 to .46 (mean $=.11)$. Again, these scores do not differ significantly.

In answer to the primary question of this thesis "In two year olds is there a significant difference between males and females over a time period of three months in rate of language growth as measured by mean length of utterance?", the answer is: No. In view of the foregoing results, it is concluded that the amount of change as measured by MLU does not differ significantly for males and females.

Non-significant differences favoring girls were found consistent with earlier studies concerning sex differences (McCarthy, 1954).

\section{Discussion}

An interesting phenomenon occurred in five of the childrens' change scores; the second sample was lower than the first in terms of MLU. In retrospect, it would have provided better reliability if each child had been measured twice in the pre-test time period and twice in the post-test time 
period. Due to normal variation occurring from one sample to another in any individual, and due to the limited size of the sample, one can only guess as to what the outcome would have been with more stable figures.

A one-tailed $t$ test for dependent measures was performed to test the significance of the Pearson $r$ correlation between the first language sample and the change score (-.71). This resulted in a $t$ value of 3.88 which is significant beyond the .005 level. This result was possibly due to the negative values in five of the change scores discussed above. For this investigation, however, these results indicate a high negative correlation between the childrens' first sample and the amount of change. The higher the MLU scores were initially, the less the amount of change as evidenced by the second sample.

The results of this investigation may have been further affected by the instructions to the mothers (see Appendix D). According to the Journal of Speech and Hearing Disorders (JSHD) Monograph number 10 (Darley, 1963), spontaneous verbalizing is a better way to elicit verbalizations from the child than questioning. It is further suggested in the monograph that the child be socially reinforced by the adult for talking and that the adult "rephrase" or repeat the child's statements. Perhaps these additional instructions to the mothers would have yielded higher MLU scores, more representative of the child's competence. A few of the mothers were hesitant to "just sit and play" with their child, which is 
possibly an indication that they were inexperienced in this type of interaction with their child or uncomfortable with the imposed structure. The additional instructions may have given them the added information necessary for more skillful interaction with their child. It is the author's impression that the mothers who exhibited apprehension when faced with the playing task had children who tended to receive lower MLU scores for both sessions and as a result lower change scores. It is possible that the children had lower scores due to the mothers' anxiety or due to an unfamiliarity with this type of interaction which resulted in less language stimulation and lower language development scores.

Finally, after the investigation had taken place, it was discovered that female "I" came from a home where the father's occupation required that he be away from home for approximately nine months of the year. Although she technically still represented a two-parent home, in actuality, her daily language experience was that of a single-mother home. The intra-group change score for the females was significant (beyond the .05 level) when her score was deleted; however, the mean change score (.31) for females with her score deleted was not significantly different from the change score for males, a finding consistent with the analysis of the differences which included her data. 


\section{CHAPTER V}

\section{SUMMARY AND IMPLICATIONS}

\section{Summary}

The purpose of this study was to examine and compare the language development rate of male and female children, 24 to 30 months of age, during a three month time period.

The research question was: in two year olds is there a significant difference between males and females over a time period of three months in rate of language growth as measured by mean length of utterance ( MLU)?

Early studies conducted in the 1930's and 1940's support sex differences in language devlopment. McCarthy (1954) reported sex differences in fourteen of these studies involving mean length of response (MLR). The differences in children under the age of three years always favored girls. McCarthy postulated that the consistency of the direction of the differences constituted a "significant trend." The studies presented in the Review of the Literature section are consistent with this "significant trend" hypothesis; the overwhelming majority show differences which favor girls.

Sixteen subjects, aged 24 to 29 months, were chosen for this study from private homes in the Greater Portland area. Each subject was sampled in the home while interacting with 
the mother.

Screening Mean Length of Utterance analysis was performed from the transcripts produced from the thirty-two examinations conducted by the investigator. Statistical analysis was by a Wilcoxon Rank Sum Test for independent measures. Non-significant differences were found which favored girls. This is consistent with earlier studies concerning sex differences (McCarthy, 1954).

\section{Implications for Future Research}

Future investigations should be performed to determine the normal distribution for this population with a measure of MLU. Lack of normative data and the possibility of dealing with truncated data (i.e., it is not possible to have an MLU of less than 1.0, which made application of a normal curve to the data from this investigation impossible) makes the determination of normal vs. non-normal population distributions impossible. Normative data on this population for the measure of MLU would allow an investigator to determine whether a small population represented a normal distribution.

Future investigations involving change scores should obtain samples more than three months apart. The intra-group change evidenced by the data presented in this investigation was not significant for males, and only significant for females when data from female "I" were omitted. This is an indication that three months may not be long enough for significant language growth to occur in this age group. 
The results of this investigation indicate that future investigations should control for first sample score effects. This result may be over-amplified because of the regression which took place in some of the childrens' change scores, and because only one baseline and one comparison measure was taken. Future MLU comparisons of longitudinal design should obtain at least two samples per measure to ensure that they are obtaining a more representative sample of the childs' language ability.

Finally, future investigators should look at all three age groups to determine the "over-all" picture, i.e., whether males and females differ from 18 to 24 months and 30 to 36 months as much or more than they did in the 24 to 30 month period included in this investigation. This strategy would be the only way to determine actual rate differences for the under-three age group. 


\section{SELECTED BIBLIOGRAPHY}

BARRIE-BLAKEIEY, S., MUSSELWHITE, C.R., and ROGISTER, S.H. Clinical Oral Language Sampling: A Handbook for students and Clinicians. Illinois: The Interstate Printers and Publishers, Inc., 1978.

BLOOM, I. Language Development: Form and Function in Emerging Grammars. Cambridge: MIT Press, 1970 .

BLOOM, I. One word at a time: The use of single-word utterances before syntax, The Hague. Holland: Mouton, 1973.

BOYD, R.D. The Boyd Developmental Progress Scale. San Bernardino, CA: Inland Counties Regional Center, Inc., 1974.

BROWN, R. A First Language. Cambridge: Harvard University Press, 1973.

DALE, P.S. Language Development: Structure and Function. Hinsdale: The Dryden Press, Inc., 1976.

DARLEY, F.I. (Ed.) Monograph supplement number 10, JSHD. 1963.

DARLEY, F.I., and WINITZ, H. Age of first word: review of research, JSHD. 1961, 26, 272-290.

EAKINS, B.W., and EAKINS, R.G. Sex Differences in Human Communication. Boston: Houghton Miffiin Company, 1978.

KLEIN, R.P., and DURFEE, J.T. Effects of sex and birth order on infant social behavior, Infant Behavior and Development. 1978, 1, 106-117.

LEE, L.I. Developmental Sentence Analysis. Evanston: Northwestern University Press, 1974.

MCCARTHY, D. The language development of the preschool child, Inst. Child Welfare Monogr. Ser., No. 4. Minneapolis: University of Minnesota Press, 1930.

MCCARTHY, D. Language development in children, In: L. Carmichael (Ed.), Manual of Child Psychology. New York: wiley, 1954.

MCCIANE, J.T. and DIETRICH, F.H. Statistics. New York: Dillon, 1982. 
MACCOBY, E.E., and JACKLIN, C.N. The Psychology of Sex Differences. Stanford: The Stanford University Press, 1974.

MATHIS, J. Comparison of amounts of verbal response elicited by a speech pathologist in the clinic and a mother in the home. Unpublished Master's Thesis, Portland State University, 1970 .

MILLER, J.F. and CHAPMAN, R.S. Research note: the relation between age and mean length of utterance in morphemes. JSHR, 1981, 24, 154-161.

MOORE, T. Language and intelligence: a longitudinal study of the first eight years. Human Development, 1967, 10, 88-106.

NICE, M., Length of sentences as a criterion for a child's progress in speech. Journal of Educational Psychology, $1925,16,370-379$.

PERKINS, W.H. Speech Pathology: An applied behavioral science. Saint Louis: The C.V. Mosby Company, 1977.

PRUTTING, C. Process: the action of moving forward progressively from one point to another on the way to completion. JSHD, 1979, 44, 3-30.

RAMER, A.I.H. Syntactic Styles in emerging language. Journal of Child Language, $1976,3,49-62$.

SCHACHTER, F.F., SHORE, E., HODAPP, R., CHALFIN, S., and BUNDY, C., Do girls talk earlier?: mean length of utterance in toddlers. Developmental Psychology, 1978, 14, 388-392.

TEMPLIN, M.C. Certain Language Skills in Children: Their Development and Interrelationships. Minneapolis: University of Minnesota Press, 1957.

WINITZ, H. Language skills of male and female children. JSHR, $1959,2,377-387$.

WORKING PAPER No. 15 Methodology and Scores of Socioeconomic status. U.S. Department of Commerce, 1960. 
A. Table 41. Brown's acquisition order for the 14 morphemes and the partial rank orders of acquisition of other investigators

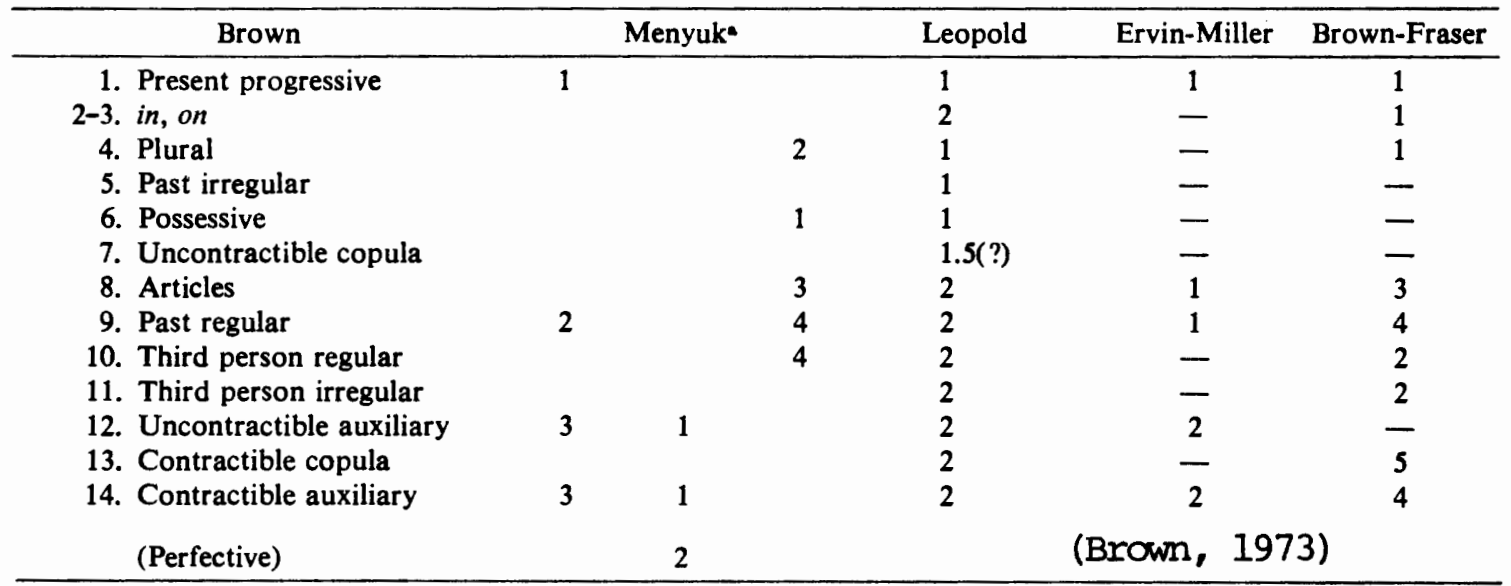

-There are three columns for Menyuk because in her rules she provides evidence relating three different small sets of morphemes with respect to one another in terms of acquisition order but does not provide evidence relating morphemes from different sets.

B. Summary of Stages for Acquisition of Semantics and Syntax

\section{Stage I} (9.18 mo.)

Semantics
frst-words learned
sre general nominals,
specific nominals,
action words
(Neleon, 1973)
Overextensions
regarding shape,
ide, function, etc.

(Clark, 1975)

\section{Functions}

performative

indicative object negative indication volition

negative volition

volitional object

agent

sction/state of agent

object

ection/state of object

dative

objec̈t assoc, with object or location

animate asac. with object or location

beation

modification of event

(Greenfield and

Smith. 1976)
Stage II

(18-24 mo.)

Semantics

2-word utterances

agent-object

agent-action

action-object

location

nomination

possessive

attributive

non-existence

rejection

denial

question

recurrence

acknowledgment

(Bloom, 1970; Brown

1973)

Syntax

2.word utterances

S.V.O.A

clause level

phrase level

(Crystal, et al,

1976)
Stage III

(2-3 yrs.)

Semantics
$3-4$ word utterances
new structures
word level
(Crystal, et al,
$1976)$

Syntax

3-4 word utterances

S-V.O-A

new structures at

clause level

new structures at

phrase level

$$
\begin{aligned}
& \text { Stage IV } \\
& (3+\text { yrs.) }
\end{aligned}
$$

Semantic

word pairs-more

and less, dimensional

terms, before and

after, verbs of $e x$ -

pression, of causa.

tion and posession

and transfer

(summarized by

Dale, 1976)

New structures at

word level

(Cryutal, et al, 1970)

\section{Syntax}

new structures at

clause and phrase

levels, recursion,

error strategies

employed (Crystal.

et al, 1970)

embeddiugs (Brom,

1973)

14 morphemes in order of acquisition: present progressive, ont, in. plural, past irregular, possessive, uncontractible copula, articles, past regular, third-persol singular regular, third-person singular irregular, uncontractihle anxiliary, cou.
Stage V

(Communicative Competence-Adult)

Cenerates and under. stands infinite combinations from a set of finite symbols (Chomsky, 1965)

\section{Prelinguistic (birth-9 mo.)}

(Prutting, 


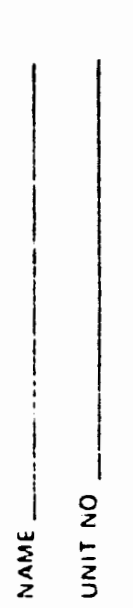

㔯 田要

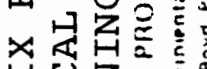

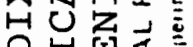
ด所思运 到我会

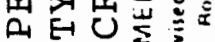
苮 以
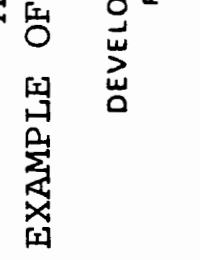
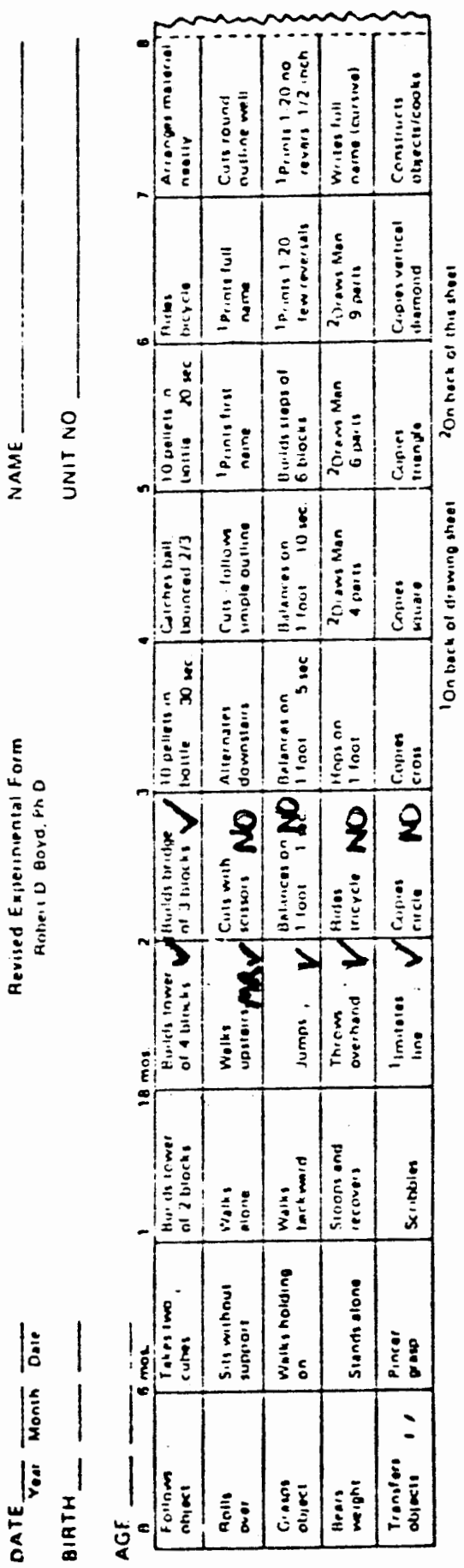

言辤
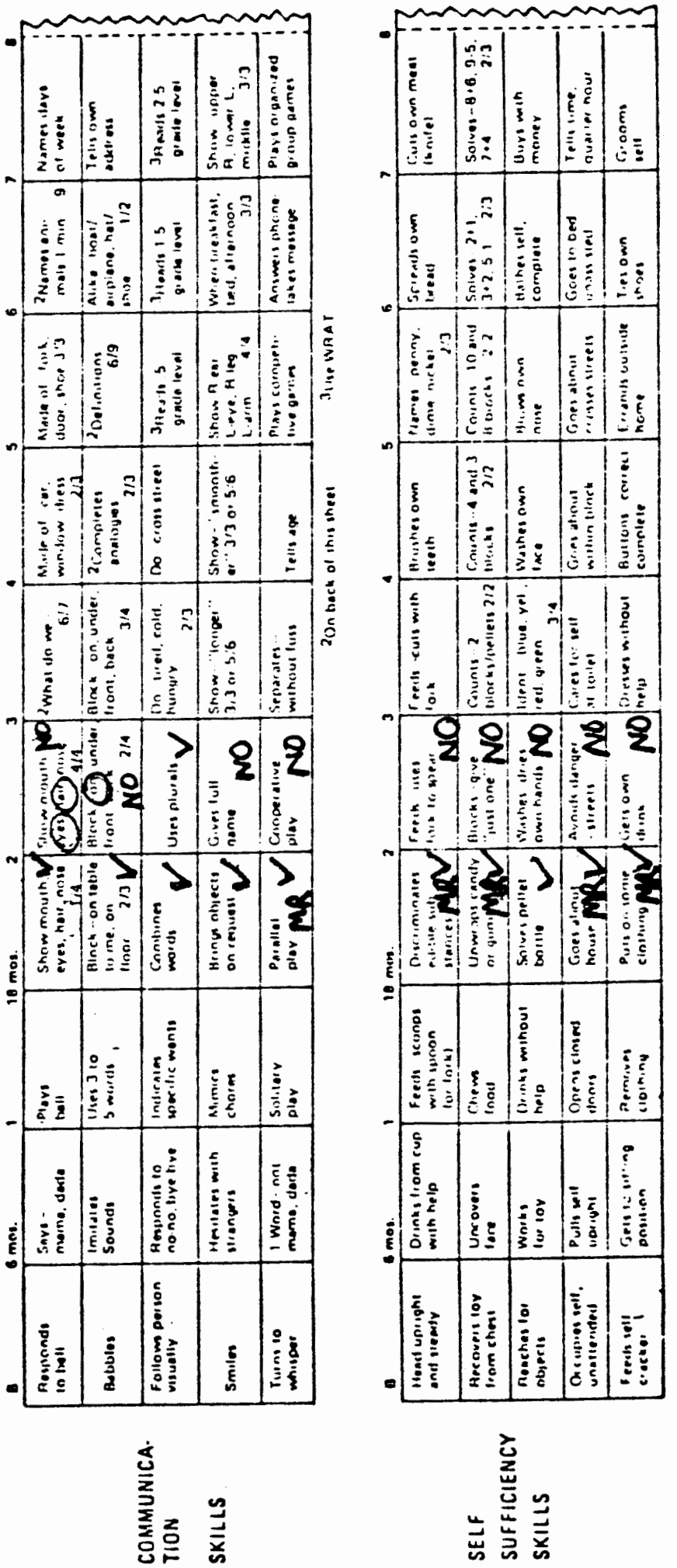


\section{APPENDIX C \\ INFORMED CONSENT LETTER}

Dear Parents:

I am a graduate student at Portland State University under the supervision of $\mathrm{Dr}$. Robert Casteel and I am conducting a study regarding the language development of preschoolers. I am attempting to find out how much change occurs in the language of children between the ages of 2 and $21 / 2$ years. The results of this study should help speech clinicians identify and subsequently provide services to preschoolers in need of language intervention.

This study can be accomplished by the following: I will tape record two language samples of your child during interaction with you in your home. Following the first taping, I will tape record once more three months later. In addition, a screening device, The Boyd Developmental Progress Scale, will be given to your child by me.

Each of the tapings will take approximately one hour. In no way will your son/daughter's name be used in reporting the results of this study. You may withdraw from this study at any time.

If you should experience problems as a result of your participation in this study, please contact Victor Dahl, office of Graduate Studies and Research, 105 Neuberger Hall, Portland State University, 229-3423.

Please sign below indicating your approval.

Thank you for your help.

Laurel Hickman

Graduate Student, Speech and

Hearing Sciences Program

Portland State University

YOUR NAME :

CHILD'S NAME:

BIRTHDATE :

PHONE :

ADDRESS :

\# OF SIBLINGS:

OCCUPATION OF PRIMARY WAGE EARNER:

YEARS OF EDUCATION OF PRIMARY WAGE EARNER:

DOES YOUR CHILD HAVE A HISTORY OF MIDDLE EAR INFECTIONS? 
APPENDIX D

LANGUAGE SAMPLE INSTRUCTIONS TO THE MOTHERS

1. Find a place in your home such as your son or daughter's room where you and your child can talk freely for thirty minutes.

2. Sit on the floor or at a table, wherever you and your child feel the most comfortable.

3. Utilize toys and books. Ask questions which require more than a one word response, such as "tell me about the story."

4. Feel free to play with any of the toys and books provided for any period of time.

5. I will not be interacting with your child during the taping. If he/she attempts to interact with me I will look the other way.

DO YOU HAVE ANY QUESTIONS ABOUT WHAT YOU ARE TO DO WITH YOUR CHILD? 
APPENDIX E

LANGUAGE STIMULATION MATERIALS

Flannel board and flannel pieces: Mr. Potato Head and

$\begin{array}{lll}\text { seal } & \text { bear } & \text { pieces: } \\ \text { mountain lion } & \text { star } & \\ \text { camel } & \text { key } & 4 \text { noses } \\ \text { kuala bear } & \text { pear } & 2 \text { eyes } \\ \text { monkey } & \text { orange } & 2 \text { lips } \\ \text { kangaroo } & \text { duck } & \text { 1 pipe } \\ \text { ladybugs } & \text { tall grass } & \text { glasses } \\ \text { pumplin } & \text { corn } & \text { hat } \\ \text { rabbit } & \text { boat } & \text { shoes } \\ \text { house } & \text { giraffe } & \text { mustache } \\ \text { fish (2) } & \text { fence } & \\ \text { lemon } & \text { cars (4) } & \\ \text { Plastic toys: } & & \\ \text { goose } & & \\ \text { ladybug } & \text { calf } & \text { Pictures: } \\ 2 \text { peiple } & 2 \text { bears } & \\ \text { hat } & \text { pig } & \text { baby calf } \\ 3 \text { chickens } & \text { horse } & \text { baby pig } \\ \text { horse w/saddle } & \text { baby duck } \\ 3 \text { matchbox cars } \text { whistle } & \text { baby kitten } \\ \text { key ring w/5 keys coin purse } & \\ 2 \text { cows } & \text { baby puppy }\end{array}$
pieces:

Flashcards :

Books :

Sesame Street Alphabet cards Sesame Street Number cards Pigs Say Oink, Alexander Sesame Street word cards Trucks and Cars Sesame street Gues Who cards Fantastic Funny Finger Book Cats: Little Tigers in Your House 
APPENDIX F

INSTRUCTIONS TO THE JUDGES

Part One: Rules

Read attached instructions to typist (investigator).

Part Two: Suggestions

The transcript that you will be working from is far from infallible. It is important that the basis for acceptance or rejection of a speech episode be the nervous system of the judge. It may be tempting to accept the transcript, especially if you agree with key words. Listen again to see if you can agree with all of the words in an episode. Especially in long episodes, it is tempting to accept the transcript without listening to each word.

It is especially important that you attend to the first pulse of an episode. The investigator may type "have one" for "I have one" for example. It is not unusual for the typist to supply a preposition or article that the child has left out. At times, you will find it beneficial to count pulses when you are uncertain as to whether to add a word or phoneme or delete a word or phoneme from the transcript.

A unit that starts as a question but ends as a statement is considered a single response unit statement. An episode that starts as a statement and ends as a question is considered a single utterance episode question (example: I think I'll is okay to tell that man//).

Word or phrasal repetitions should be excluded if they represent natural non-fluencies as opposed to repeating for stress or elaboration. Vocal pauses are excluded.

(Mathis, 1970) 
Transcript Typist Instruction

In a speech situation between an adult and a child, tape recordings have been made. These tape recordings are the only information we have regarding the conversation taking place between these two people; so, for this reason, it is critical that the typing be accurate. There are certain general and specific instructions that have been adhered to at all times in transcribing these tape recordings.

A. General Instructions

1. Use the letter $M$ to designate utterances by the mother, and use the letter $c$ to designate an utterance by the child.

2. Do not use standard punctuation, other than apostrophes, which are to be used to indicate the possessive case or contractions.

3. Any utterance or part of utterance which you cannot comprehend after diligent effort to determine what is being said, omit that entire episode from the transcript, even one word in an otherwise intelligible utterance. Since the language of children is not predictable by adult standards, one should not over rely on context clues for unclear or missing words. Many factors may contribute to the utterance being unintelligible: too low an intensity of utterance, environmental noise, speech defect, two people talking at once or the recorder is malfunctioning. Do note that an unintelligible episode has occurred.

4. The speech utterance need not be a complete thought; but, if all words are intelligible, include the utterance as one speech episode.

5. At times, you will find both the adult and the child talking at the same time. First type the complete utterance of the person being interrupted and, then, type the other speaker's utterance.

6. Certain utterances are not meaningful words but are vocal pauses, such as er, ah, andah, um, etc. Do not type vocal pauses.

7. Some words acoustically similar to meaningless interjections are considered as real words and should be typed, such as huh-uh, uh-huh, hm, or animal sounds which are used in lieu of the name of the animal in a thought.

8. Utterances which appear to be clearly enumerative, if separated by pauses, are considered separate utterance units.

B. How to mark the Transcript

1. Indicate the beginning word of any speech episode 
by underlining it; and make the appropriate ending which is a single slash (/) for a statement and a double slash $(/ /)$ for a question.

2. It is important that even if the episode is composed of only one morpheme, it must be underlined and followed by the appropriate slash.

3. It is important to remember that each speaker must be designated appropriately and accurately.

c. Criteria for Counting Words

1. Brown (1973) see pages 22-23.

2. In addition to the above, the following rules were used in scoring:

a. Contractions of the subject and predicate like it's and what's are counted as two morphemes.

b. Contractions of the verb and the negative like "can't" are counted as one morpheme.

c. All expressions of negation, of affirmation, or of interrogation will be counted as one morpheme. Examples would be such expressions as: uh-huh, oh oh, or uh uh.

d. As in compound nouns, slang expressions which appear as single units (my gosh) will be treated as one morpheme. 


\section{APPENDIX G}

INTRA-GROUP ANALYSIS

THE WILCOXON SIGNED RANK TEST

FOR A PAIRED EXPERIMENT

FEMALES

\begin{tabular}{cccccc}
\hline FEMAIE & $\begin{array}{c}\text { SESSIOI } \\
\# I\end{array}$ & $\begin{array}{c}\text { SESSION } \\
\# 2\end{array}$ & CHANGE & RANK & $\begin{array}{c}\text { WITHOUT } \\
\text { F "I" }\end{array}$ \\
\hline A & 1.66 & 1.60 & .06 & 2 & 2 \\
B & 1.62 & 1.96 & -.34 & 5.5 & 5.5 \\
C & 1.90 & 2.24 & -.34 & 5.5 & 5.5 \\
D & 2.10 & 2.74 & -.64 & 8 & 7 \\
E & 2.00 & 2.28 & -.28 & 4 & 4 \\
F & 2.08 & 2.12 & -.04 & 1 & 1 \\
G & 1.54 & 2.28 & -.74 & 9 & 8 \\
H & 1.94 & 2.06 & -.12 & 3 & 3 \\
I & 3.62 & 3.10 & .52 & 7 & \\
\hline
\end{tabular}

MALES

\begin{tabular}{lllll}
\hline MALE & & & \\
\hline A & 1.94 & 1.64 & .30 & 4 \\
B & 1.30 & 1.76 & -.46 & 7 \\
C & 1.40 & 1.74 & -.34 & 6 \\
D & 1.28 & 1.58 & -.30 & 4 \\
E & 2.86 & 2.74 & .12 & 1 \\
F & 1.82 & 2.12 & -.30 & 4 \\
G & 2.96 & 2.74 & .22 & 2 \\
\hline
\end{tabular}




\section{APPENDIX H}

INTER-GROUP ANALYSIS

THE WILCOXON RANK SUM TEST

FOR INDEPENDENT SAMPLES

\begin{tabular}{crrl} 
FEMALES & CHANGE & \multicolumn{2}{c}{ RANK } \\
\hline A & -.06 & 5 & $(4)$ \\
B & .34 & 12 & $(11)$ \\
C & .34 & 12 & $(11)$ \\
D & .64 & 15 & $(14)$ \\
E & .28 & 8 & $(7)$ \\
F & .04 & 6 & $(5)$ \\
G & .74 & 16 & $(15)$ \\
H & -.52 & 1 &
\end{tabular}

\begin{tabular}{cccl} 
MALES & CHANGE & \multicolumn{2}{c}{ RANK } \\
\hline A & -.30 & 2 & $(1)$ \\
B & .46 & 14 & $(13)$ \\
C & .34 & 12 & $(11)$ \\
D & .30 & 9.5 & $(8.5)$ \\
E & -.12 & 4 & $(3)$ \\
F & .30 & 9.5 & $(8.5)$ \\
G & -.22 & 3 & $(2)$
\end{tabular}

